\title{
Exploring research issues in selected forest journals 1979-2008
}

\author{
Michèle Kaennel DobBERTIN ${ }^{1 *}$, Michael Peter NoBIS ${ }^{1}$
}

(Received 19 March 2010; accepted 14 July 2010)

Keywords:

bibliometrics /

forest research /

peer-reviewed publications /

principal component analysis /

research trends

\begin{abstract}
- Forest science and policy have experienced significant changes under the pressure of global change. Assuming that scientific publications mirror contemporary issues, our objective was to verify whether titles of articles show a temporal trend, and whether it coincides with the new agenda set by sustainable forest management.

- We used ISI Web of Science to collect articles published 1979-2008 in 6 peer-reviewed forest(ry) journals $(n=20677)$. We split titles into strings and processed them to increase the homogeneity of our sample. We applied principal components analysis (PCA) as an indirect gradient analysis. We also searched titles for words related to the social, political and economic components of forestry.

- The PCA ordination revealed a dominant and distinct time gradient in the use of title words in our corpus. A few words have disappeared, but those with a positive trend clearly dominate, reflecting an opening of forest science towards more process-oriented research, especially in ecology and environmental and climate change. However, socio-economic aspects are still underrepresented.

- In our study, titles of forest(ry) publications increasingly include topics from neighboring natural sciences, but still very few from socio-economic disciplines.
\end{abstract}

\section{INTRODUCTION}

Forest science and policy have experienced significant changes in the last two decades. Their agenda is expected to consider global change, biodiversity conservation and resource depletion. These interconnected issues are reflected in the three dimensions of sustainable forest management - environmental, social and economic (Adams, 2006).

International programs have been implemented to address these concerns. Several authors and collectives have expressed their vision for more cross-sectoral, participatory, multidisciplinary approaches, as well as better integration between science, policy and implementation. Others consider that the required changes still pose a real challenge to forest science (Andersson et al., 2005; Glück, 2004; Hickey and Nitschke, 2005; Innes, 2005; Konijnendijk, 2004).

To which extent has forest research adapted to the new global agenda? And, assuming that scientific literature reflects contemporary issues in academia, which trends can be inferred from a large sample of peer-reviewed publications? To answer these questions, we have adapted some of the methods developed by Nobis and Wohlgemuth (2004) to analyze titles and abstracts of articles from five core journals of ecology. To our knowledge, a similar study had yet to be done on forestry and forest-related research.

* Corresponding author:michele.kaennel@wsl.ch, Swiss Federal Research Institute WSL, Zürcherstrasse 111, 8903 Birmensdorf, Switzerland.
Our general objective was to identify temporal trends in forest research issues over the past $30 \mathrm{y}$. We chose to restrict our study to journals, as they are consistent and wellcircumscribed repositories of knowledge. We included the 1980s in order to identify shifts after the Rio Conference. We were especially interested in exploring whether journals whose scope is limited to forestry and forest research have recently opened up to disciplines such as ecology or socioeconomics.

We expected to answer the following questions: (1) does a word analysis reveal a general trend in the use of title words in forest(ry) journals over the last 30 y (1979-2008)? (2) Can we identify "losers" and "winners", i.e., words referring to issues that have disappeared from or emerged in forest(ry) literature? (3) Can we identify a paradigm shift reflecting the new agenda in forest(ry) research?

\section{MATERIALS AND METHODS}

\subsection{Data collection}

Our analysis is based on a corpus of six journals in forestry and forest research and covers a 30-y period (1979-2008). We used ISI Web of Science (hereafter WoS) to query our data. In order to identify forestry and forest research journals stricto sensu, we first singled out the 39 journals belonging exclusively to the subject category "Forestry" in WoS. We then applied the following selection criteria: (1) the journal has been indexed in WoS for at least $30 \mathrm{y}$; (2) its 
impact factor in 2008 was above 0.918 , which was the median impact factor for all journals of the category "Forestry"; (3) it has English titles. We excluded Journal of Forestry to avoid over-representation of single countries in authorship because $92 \%$ of the articles published in this journal had at least one US-American author. In the other selected journals, this figure reached at most $75 \%$ for a given country.

Our selection resulted in six journals: Annals of Forest Science, Canadian Journal of Forest Research, Forest Ecology and Management (=FEM), Forest Science, Forest Pathology, and Forestry. In 2008, their impact factors ranged between 1.225 and 2.110 .

We used WoS to query titles $(n=20677)$ of all articles published between 1979 and 2008 in these journals. During this period, the number of articles increased on average by $4.3 \%$ per year. In contrast the average number of words per title increased by only $0.8 \%$ per year.

\subsection{Data processing}

We first split titles into single strings $(n=286589)$ and stored these into a database. We unified British and American spellings, and singular and plural forms. We addressed the issue of compound words as follows: (a) we searched for hyphenated compound words made up of two words, such as "dead-wood"; (b) we searched for the same consecutive words "dead wood" and replaced the space by a hyphen; (c) we searched for the same compound word "deadwood" and split it into "dead-wood" (see Nobis and Wohlgemuth, 2004 for detailed methodology).

All strings resulting from word processing are hereafter called "words". We filtered out stop-words, i.e., articles, prepositions or other words we considered not significant (see list in online Appendix 1 available at www.afs-journal.org). Finally, we narrowed our sample to words appearing in at least 25 titles, without distinction by journal. The resulting data set contains 1207 unique title words corresponding to 125679 occurrences in 6 journals $\times 30 \mathrm{y}$ observations.

\subsection{Data analysis}

We applied principal components analysis (PCA) as an indirect gradient analysis to our data set in order to identify temporal gradients in the use of title words. As in Nobis and Wohlgemuth (2004), PCA was calculated based on the correlation matrix of log-transformed, relative title-word frequencies per year (average number of occurrences in 1000 title words per year, in order to take the steady annual increase in title numbers and number of words per title into account). In a second step, we focused on the 150 title words that correlate best with the axes of the detected data structure that was interpreted as time gradient. These 150 words are hereafter called "trend words". PCA was calculated using CANOCO 4.5 software (ter Braak and Šmilauer, 2002).

Since our PCA-approach cannot highlight uncorrelated or absent words, or words with a low number of occurrences (in our case, less than 25 occurrences in titles), we examined a few words that did not appear among the 150 trend words, and that we selected subjectively. In particular we searched the unprocessed titles for 15 words related to the social, political and economic aspects of forestry ("community", "conflict", "econometric", "economic*", "financial*”, "governance", "investment", "market", "owner", "participat*”, "recreation", "society", "socio-economic", "stakeholder", and "stewardship", including plural of all nouns). "Community" appeared in 312 titles but we filtered out 284 titles where it was used in an ecological context instead of its sociological meaning.

\section{RESULTS}

The main data structure in relative title-word frequencies between publication years is displayed as ordination biplot in Figure 1. The distinct horseshoe effect of the two main ordination axes expresses a dominant gradient in the data from the first quadrant Q1 (years 1979-1983) to the last quadrant Q4 (years 1999-2008). This gradient clearly represents a time gradient and the first two PCA axes account together for $32.1 \%$ of the variation in the data. The neighborhood of the publication years represents the time period where the relative frequencies of these trend words are highest.

Table I presents the 150 trend words numbered in ascending order according to their angular position in the four quadrants. We define "losers" as the trend words in quadrants Q1 and Q2, while "winners" are trend words in Q3 and Q4. We then extracted the 50 "strongest" trend words, i.e., those most strongly correlated with the first two PCA-axes (bold face in Tab. I). Among these, only 12 are losers (see examples in Fig. 2A), whereas 38 are winners (examples in Fig. 2B).

Among the 15 words we deliberately looked for, only "economic", "financial", "investment" and "market" occurred more than 25 times in the processed titles, and none of them was a trend word. Counts in unprocessed titles showed that "governance" or "participative" were even completely absent.

\section{DISCUSSION}

The PCA ordination reveals a dominant and distinct time gradient in the use of title words in our corpus of journals. It allowed us to identify words with either negative (losers) or positive (winners) trends, and to quantify these trends in order to focus on the trend words with the highest correlation with the detected data structure. Hereafter we discuss several groups of winners and losers that we consider representative of changes in forest(ry) research issues or approaches.

\subsection{Losers}

Losers can be interpreted as indicators of decreasing relevance of research issues. One striking example is "SO-2", which has not been mentioned in titles in our corpus since 1996. This turning point occurred a few years after the critical acid loads in Europe had been reduced to less alarming levels (Hettelingh et al., 2005; online Appendix B1 available at www.afs-journal.org) and after the acid rain and forest dieback debate had receded in Europe and North America.

In contrast, other words may have fallen off because they have become too trivial as titles have gained in informativeness, as is the case when a research field matures (White and 


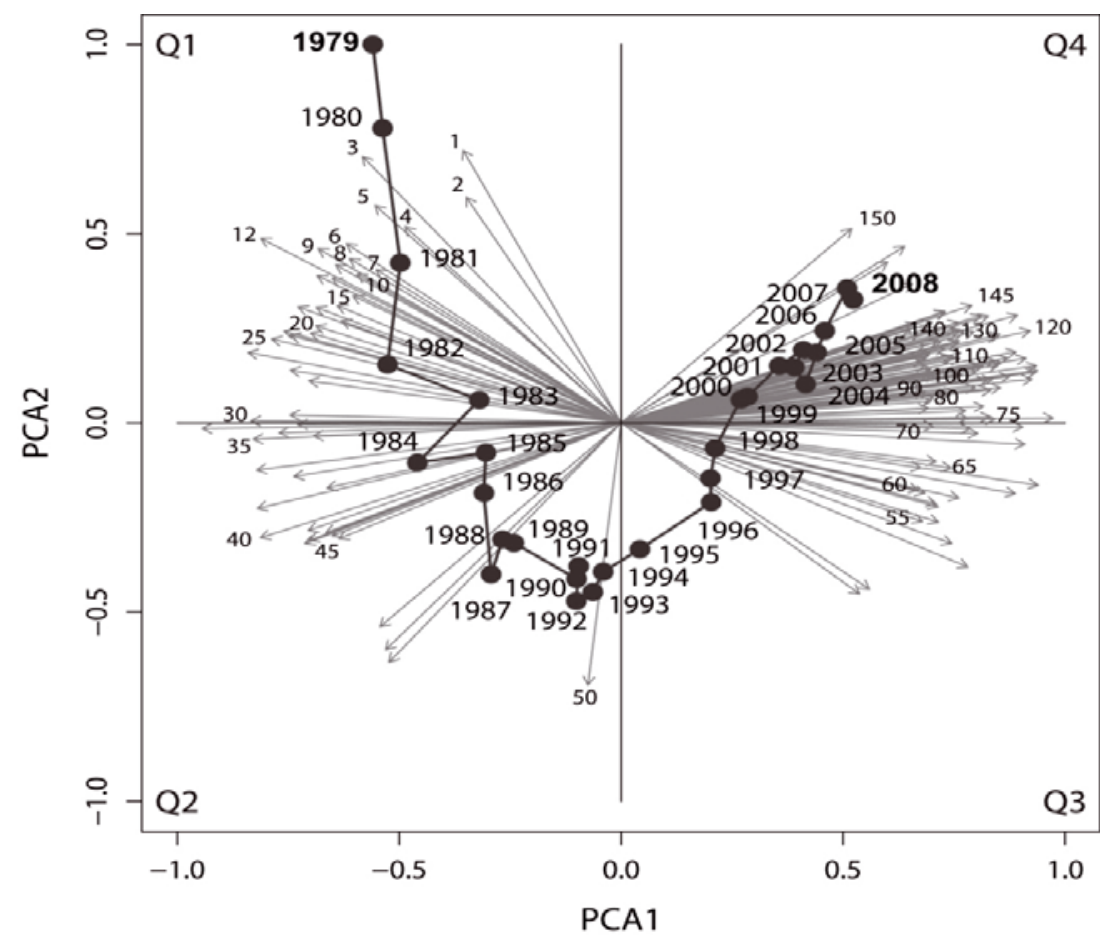

Figure 1. PCA biplot using log-transformed, relative counts of title words per year. The first and the second PCA axes accumulate $25.6 \%$ and $6.5 \%$ of total variance, respectively. Numbers refer to 150 best fitting title words as listed in Table I.

Table I. List of 150 trend words: the 50 most important words, i.e., with the highest correlation, are in bold.

\begin{tabular}{|c|c|c|c|c|c|c|c|}
\hline Q1 & & 36 & PINE-SEEDLINGS & Q4 & & 111 & DEBRIS \\
\hline 1 & IDAHO & 37 & IN-VITRO & $72 *$ & IMPACT & 112 & COARSE-WOODY \\
\hline 3 & FOMES-ANNOSUS & 39 & NEEDLE & 74 & TOOL & 114 & MANAGEMENT \\
\hline $4^{*}$ & SEASONAL-CHANGES & $40 *$ & SEEDLING & 75 & CANADA & 115 & BRAZILIAN \\
\hline $6^{*}$ & WEIGHT & 42 & PHOTO-SYNTHESIS & 77 & FOREST-MANAGEMENT & 117 & AMAZON \\
\hline 7 & COTTON-WOOD & 43 & YOUNG & 78 & TREE-GROWTH & $118^{*}$ & IMPLICATION \\
\hline 8 & SYMPTOM & 44 & GROWTH & 79 & HETEROGENEITY & 119 & ABUNDANCE \\
\hline 9 & CANKER & 45 & STOMATAL & $80^{\circ}$ & USING & 120 & SPAIN \\
\hline 12 & DISEASE & 48 & BUD & $83^{\circ}$ & LOCAL & 123 & CHINA \\
\hline 13 & PINE-BEETLE & 49 & LOBLOLLY-PINE & 84 & FIRE & 124 & SYLVATICA \\
\hline 14 & ROOT-ROT & 50 & SEED-ORCHARD & 85 & VEGETATION & 125 & LINKING \\
\hline 15 & PINUS-RESINOSA & & & 86 & CASE-STUDY & 126 & SEQUESTRATION \\
\hline 16 & MONOTERPENE & Q3 & & $87^{\circ}$ & DIVERSITY & 127 & SUB-BOREAL \\
\hline 17 & CONE & 51 & TEMPORAL & 88 & GAP & 128 & SILVICULTURAL \\
\hline 18 & WHITE-PINE & 52 & CHANGE & 89 & EUCALYPTUS-GLOBULUS & 129 & SUB-TROPICAL \\
\hline 19 & FORMATION & 53 & TROPICAL & 90 & QUERCUS-SUBER & 130 & RECRUITMENT \\
\hline 20 & DORMANCY & 54 & TREE-SPECIES & 91 & DISTURBANCE & 131 & ABIES \\
\hline 21 & MISTLETOE & 55 & CENTRAL & 92 & MANAGED & $132^{\circ}$ & LANDSCAPE \\
\hline 22 & CAUSED & $56^{*}$ & RAIN-FOREST & 93 & FOREST & 133 & BUFFER \\
\hline 23 & ECTOMYCORRHIZAE & 57 & REGENERATION & 94 & USA & 134 & DEAD-WOOD \\
\hline 24 & WESTERN-HEMLOCK & 58 & ASSESSMENT & 95 & ANTHROPOGENIC & 135 & RESTORATION \\
\hline 25 & so-2 & 59 & EUROPEAN & 96 & BIRD & 136 & FOREST-LANDSCAPE \\
\hline 26 & SEED & 60 & BRAZIL & $97^{\circ}$ & BIODIVERSITY & 137 & COMPOSITION \\
\hline 27 & CORRECTION & $61 *$ & LONG-TERM & $98^{*}$ & RIPARIAN & 138 & FOREST-STRUCTURE \\
\hline 28 & ISOLATE & $62{ }^{\circ}$ & DYNAMIC & 99 & COMMUNITY & 139 & MICROSATELLITE \\
\hline 29 & SHOOT & $63 \cdots$ & MODELING & 100 & STAND-LEVEL & $140^{*}$ & ASSEMBLAGE \\
\hline \multirow{2}{*}{$30 *$} & STUDY & 64 & BRITISH-COLUMBIA & 101 & HABITAT & 141 & CHAMAECY-PARIS \\
\hline & & 65 & BARK-BEETLE & 102 & ETHIOPIA & 142 & FOREST-HARVESTING \\
\hline Q2 & & 66 & CONSERVATION & $103^{*}$ & ACROSS & 143 & SUSTAINABILITY \\
\hline 31 & FIR & 67 & OLD-GROWTH & 104 & SAVANNA & 144 & DENSITY \\
\hline 32 & DOUGLAS-FIR & 68 & STRUCTURE & 105 & SUSTAINABLE & 145 & INDICE \\
\hline 33 & CONTAINER-GROWN & 69 & GRADIENT & 106 & SPRUCE-PICEA & $146^{\circ}$ & TEMPERATE \\
\hline 34 & ESTIMATION & 70 & MIXED-SPECIES & 107 & MEXICO & 147 & PATTERN \\
\hline \multirow[t]{3}{*}{35} & ROOT & 71 & CARBON & 108 & UNDER-STORY & 148 & WILD-FIRE \\
\hline & & & & 109 & MIXED-WOOD & 149 & JAPAN \\
\hline & & & & 110 & NATIVE & 150 & TREE-REGENERATION \\
\hline
\end{tabular}

* Title words $(n=17)$ that were also among the 150 trend words in a previous study based on ecology journals (Nobis and Wohlgemuth, 2004); ** title words $(n=6)$ that were among the 50 strongest trend words in that previous study. 

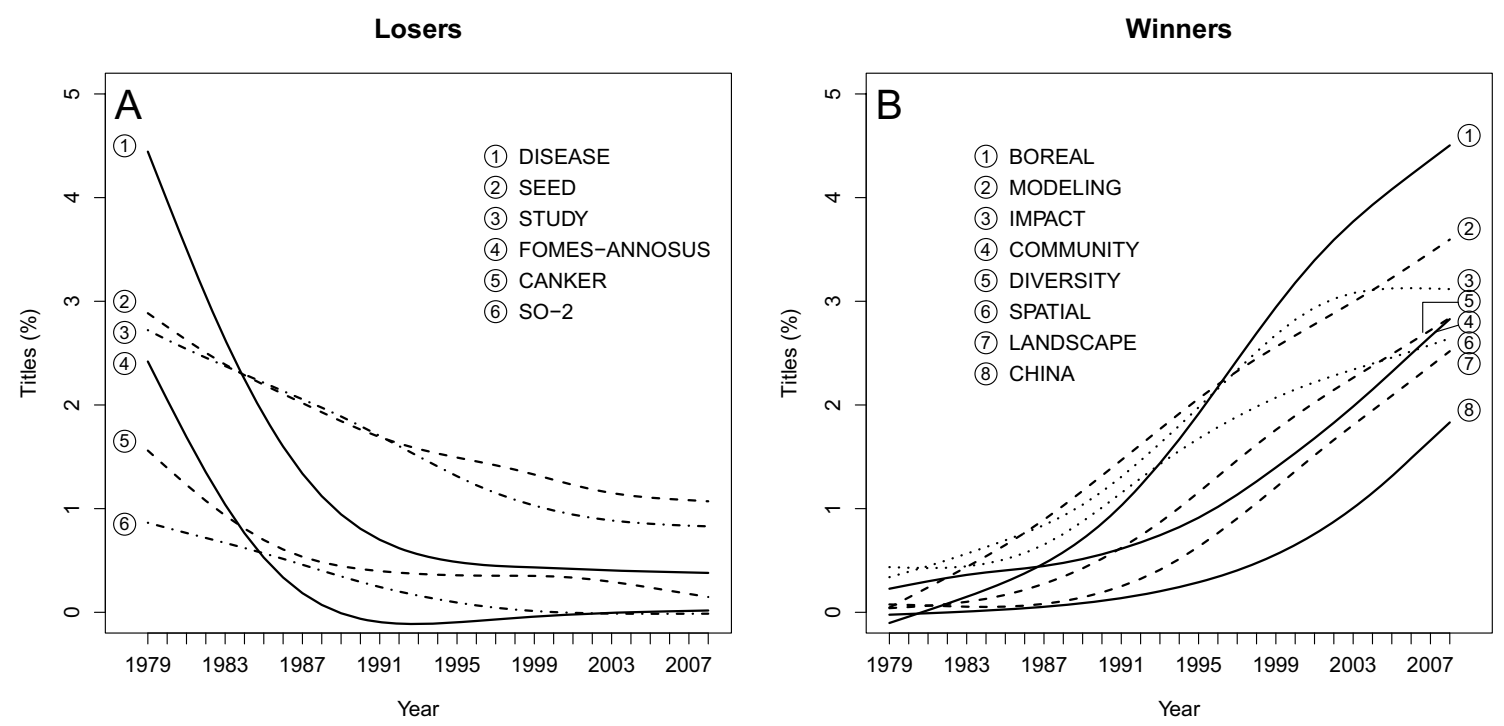

Figure 2. Examples of temporal trends in relative frequencies of selected trend words representing losers (A) and winners (B), respectively. Fitted curves are calculated by cubic smoothing splines $(\mathrm{df}=4)$.

Hernandez, 1991). For example, the marked decline of "study" both in the present paper and in Nobis and Wohlgemuth's article (2004) may illustrate that ecology and forest(ry) research have become less descriptive. Losers such as "disease" and "canker" may have been replaced in titles by a more precise terminology, e.g., the names of the pathogens or diseases. Similarly, the disappearance of "Fomes annosus" coincides with a change in nomenclature, when this fungus was renamed Heterobasidion annosum (Soutrenon and Delatour, 1998).

In addition to the losers shown in Figure 2A, another group of negative trend words related to tree physiology is concentrated around the mid-1980s like, e.g., "photosynthesis" or "stomatal". This cluster coincides with the launching of Tree Physiology in 1986 - a journal not included in our corpus. Indeed, titles of articles published in that journal since 1986 contain over $50 \%$ of occurrences of "photosynthesis" or "stomatal" in all journals in the "Forestry" subject category in WoS. A fading of physiology-related words in our corpus is therefore likely to be induced less by a loss of topicality than by the creation of new specialized journals (Aussenac, 2002).

The poor ranking or absence of economic, social and policy-related words may also be explained by the fact that other, specialized journals attract articles in these disciplines. In the "Forestry" category of WoS, however, only Forest Policy and Economics, launched in 2000, and Journal of Forest Economics, launched in 1994, explicitly cover the economic and political aspects. Sociological studies are not mentioned in their scope. Thus, there is no specialized outlet in the "Forestry" category of WoS that could divert sociological studies from forestry journals. In contrast to the physiologyrelated words, no economic words appeared in our PCA around the time of these launchings. This supports warnings that the new (post-Rio) forestry paradigm requires yet a more comprehensive level of understanding of social issues (Innes,
2005) and more socio-economic and policy-oriented research (Seppälä, 2004).

These few cases exemplify various reasons why words may vanish in titles: they can refer to decreasing relevance of research issues, or their disappearance corresponds to a terminological shift, or they express an orientation of authors towards new journals. As for title-words related to economic, political and sociological issues, their quasi-absence can infer that interdisciplinarity with forest(ry) research is indeed still weak.

\subsection{Winners}

In contrast to the well-balanced distribution of the years (16 $\mathrm{y}$ in Q1 and Q2 vs. $14 \mathrm{y}$ in Q3 and Q4 in Fig. 1), the 100 winners of quadrants Q3 and Q4 are obviously more numerous than the 50 losers. A similar contrast was discussed by Nobis and Wohlgemuth (2004) in their study based on ecology journals. We have identified several groups of winners, which we consider representative of recent trends.

The first obvious feature of our results is the large number of ecology-related words among the strongest winners in Q4 (bold face in Tab. I). Words such as "community" and "diversity", shown as examples in Figure 2B, or "disturbance", "habitat" and "sustainable" took off in the mid-1990s, i.e., shortly after the Earth Summit in 1992. "Landscape" and "forest-landscape" mirror the upsurge of landscape ecology as a theoretical foundation for the sustainable forest management (Mendoza et al., 2005; Schlaepfer, 1997). "Spatial", "local", "pattern", "long-term" exemplify issues related to spatial and temporal scales, which are critical when quantifying landscape or stand heterogeneity. "Across" was interestingly associated in one third of its occurrences with "gradient" or "scale" and is therefore rather a sense-bearing word than a stop-word.

"Modeling" was a plain winner both in our study and in the 2004 study based on ecology journals. Among the 150 trend 
COMMUNITY

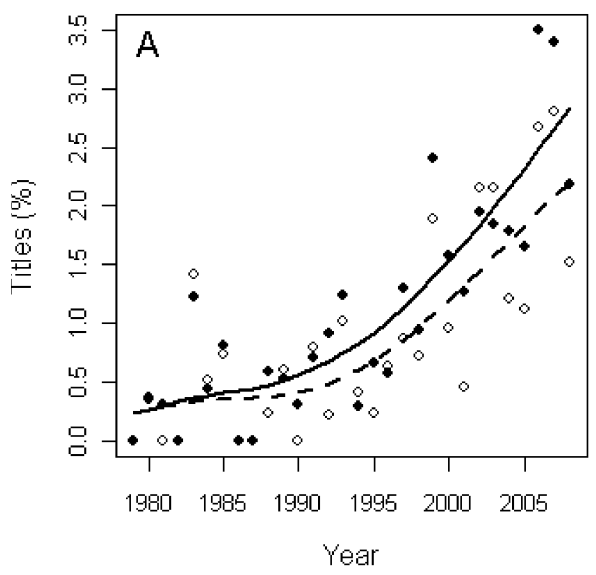

LANDSCAPE

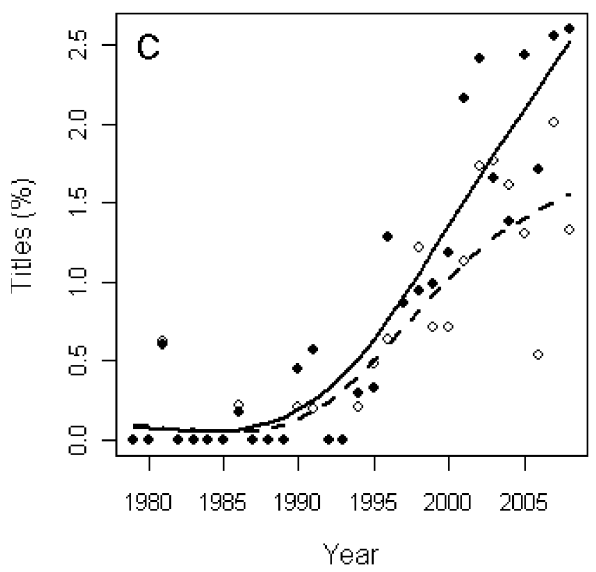

DIVERSITY

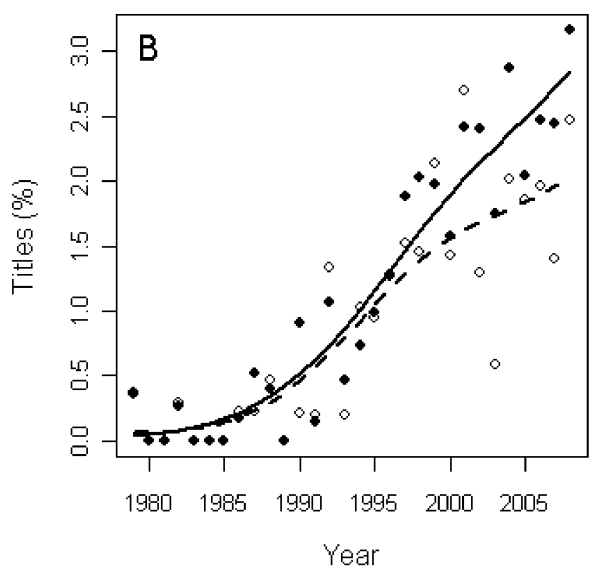

SUSTAINABLE \& SUSTAINABILITY

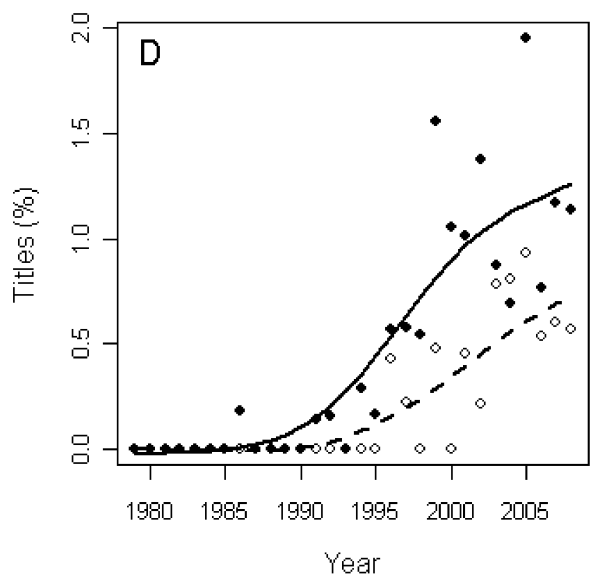

Figure 3. Relative frequencies of selected ecology-related trend words and the influence of the journal Forest Ecology and Management (FEM). Solid symbols and solid curves represent data of all six journals; open symbols and dashed curves refer to relative frequencies without FEM. Fitted curves are based on cubic smoothing splines $(\mathrm{df}=4)$.

words, it is the only one referring to a research method or technique. Its annual number of occurrences in titles has been steadily increasing until reaching since 2005 levels comparable to the sum of occurrences of "model", "simulation model" and "growth model", whereas these three words have been losing ground. The high scores of "modeling" can be attributed to the rapid development of new methods in statistics, the increased computing power and the need to account for more complex interactions (Houllier, 2004). In addition, "modeling" has a strong potency as a buzzword in titles, as opposed to the most passive and traditional connotations of "model".

"Biodiversity", a popular buzzword in ecological literature, appeared in our corpus in 1992, five years after its first mention in WoS ever. Since then, it has occurred in only $0.3 \%$ of titles on yearly average. In contrast, "diversity" has climbed much faster and is even one of the strong winners (in bold in Tab. I). Obviously, authors realized that titles were more ef- ficient when they contained precise terminology rather than "biodiversity" (Kaennel, 1998).

At first sight, the strong increase in ecology-related words may seem to be related to the high proportion $(35.25 \%)$ of titles from FEM in our sample, as this journal focuses on forest ecology. Indeed, without the articles published in this journal, words such as "community" or "landscape" would score approximately half as many occurrences in absolute counts. However, these and others of the strongest ecologyrelated winners show a strikingly similar distribution of relative counts when FEM is excluded from our corpus (Fig. 3). Thus, the ecology-related trend is influenced by FEM but clearly not generally driven by this journal.

Another group of winners is the one led by "boreal", which is the trend word with the fastest growth in our analysis. In over $50 \%$ of its occurrences, it is associated with words related to climate change ("carbon", "sequestration") or its consequences ("fire", "insect", "storm", "permafrost"). It also 
appears in titles dealing with ecological issues. Besides, over $70 \%$ of the 521 articles containing "boreal" in their title have at least one author affiliated in Canada. However, since the climate change debate started raging in the 1990s, the interest and concern for boreal forests as potential victims of climate change and as carbon sinks have been growing worldwide. We therefore connect this upsurge to the climate change issue. Indeed, "carbon" is also one of the strong winners. Interestingly, its number of occurrences follows the temperature curve in the Northern Hemisphere, as shown in online Appendix B2. As for "climate change", its strength of correlation was just slightly below the threshold of the 150 trend words, which may indicate that authors consider it as a less informative title-word or even as a buzzword.

Among our winners, four ("long-term", "modeling", "impact", and "boreal") were also among the 50 strongest trend words identified by Nobis and Wohlgemuth (2004) in their study based on ecology journals.

In conclusion, the winners with the strongest trend clearly reflect an opening of forest(ry) research towards ecology as well as environmental and climate change. The emergence of these trends corresponds with that of sustainable forest management after the Earth Summit and can hardly be considered a pure coincidence.

\subsection{Do titles reflect a paradigm shift in forest(ry) science?}

As far as forest(ry) science is concerned, the Rio agreements imply: (1) interfacing with other natural sciences, in particular ecology; (2) taking into account the climate change issue; and (3) developing the dialogue with social sciences. Most recent definitions of forest(ry) science include the biological, ecological, managerial, as well as social sciences (e.g., Helms, 2002). Our results, however, suggest a more nuanced picture. The winners of the last fifteen years do reflect an opening of journals toward ecology and climate-change related issues as well as a shift up to broader spatial and longer temporal scales.

However, social, economic and political aspects are still underrepresented. In particular, the social component is almost missing in our sample. This confirms the analyses of several authors (Andersson et al., 2005; Innes, 2005; Jansen, 2008; Mulloy, 2004; Seppälä, 2004). However, the integration of social components and the expansion of interdisciplinarity probably face common obstacles. Some of these barriers are cultural, others are related to the traditional partitioning of research and teaching activities in discipline-based departments. This segmentation is still mirrored in funding organizations, professional societies and journals (Committee on Science, Engineering, and Public Policy, 2005; Glück, 2004).

In short, the trends in the last $15 \mathrm{y}$ of our sample reflect only some of the changes requested by the Earth Summit. And they definitely do not have the magnitude of an "intellectually violent revolution", as in Kuhn's definition of paradigm shift (1962).

\section{CONCLUSIONS}

By applying an indirect gradient analysis (PCA) to title words from a sample of six forest(ry) journals, we have shown a clear time trend in these title words. Some have disappeared, and with them the concepts and issues they represent, either for lack of topicality or because they were attracted by new, more specialized journals. Other issues, especially those related to climate-change and ecology, have increasingly been used in the past fifteen years. With respect to these issues, a new research agenda has obviously been set up to develop a broader knowledge base and to account for the multi-functionality of forests as one of the pillars of sustainable forest management. However, socio-economic aspects are still underrepresented.

Acknowledgements: We are thankful to Matthias Dobbertin for stimulating comments in an earlier version of our manuscript and two anonymous reviewers whose suggestions led to substantial reformulation of the arguments presented here.

\section{REFERENCES}

Adams W.M., 2006. The future of sustainability: re-thinking environment and development in the twenty-first century, Report of the IUCN Renowned Thinkers Meeting, 29-31 January 2006, http://cmsdata. iucn.org/downloads/iucn_future_of_sustanability.pdf, retrieved on: 2010-06-24.

Andersson F., Angelstam P., Feger K.H., Hasenhauer H., Kräuchi N., Marell A., Matteuci G., Schneider U., and Tabbush P., 2005. A research strategy for sustainable forest management in Europe, Groupement d'Intérêt Public Ecosystèmes Forestiers, Paris, 149 p.

Aussenac G., 2002. From the "Annales de l'École Nationale des Eaux et Forêts" to the "Annals of Forest Science", eighty years of forestry science publications in France. Ann. For. Sci. 59: 789-793.

Committee on Science, Engineering, and Public Policy (COSEPUP), 2005. Facilitating interdisciplinary research. Nat. Acad. Press, Washington, D.C., 332 p.

Glück P., 2004. Response to "The role of research in the MCPFE" Research needs in the pan-European process: the role of EFI. In: Baines C. (Ed.), Forest Research Crossing Borders. EFI Proc. 50: 97-101.

Helms J.A., 2002. Forest, forestry, forester. What do these terms mean? J. For. 100: 15-19.

Hettelingh J.P., Posch M., and Slootweg J., 2005. Status of European critical loads and dynamic modelling. In: Hettelingh J.P., Posch M., and Slootweg J. (Eds.), CCE Status Report 2005, Coordination Centre for Effects, Bilthoven, Netherlands, pp. 9-26.

Hickey G.M. and Nitschke C.R., 2005. Crossing disciplinary boundaries in forest research: an international challenge. For. Chron. 81: 321323.

Houllier F., 2004. How to respond to emerging research needs in Europe? In: Baines C. (Ed.), Forest research crossing borders. EFI Proc. 50: $137-142$.

Innes J.L., 2005. Multidisciplinarity, interdisciplinarity and training in forestry and forest research. For. Chron. 81: 324-329.

IPCC, 2007. Climate Change 2007: Synthesis Report. Contribution of Working Groups I, II and III to the Fourth Assessment Report of the Intergovernmental Panel on Climate Change [Core Writing Team, In: Pachauri R.K and Reisinger A. (Eds.)]. IPCC, Geneva, Switzerland, $104 \mathrm{p}$.

Jansen G., 2008. Communication between forest scientists and forest policy-makers in Europe - a survey on both sides of the science/policy interface. For. Policy Econ. 10: 183-194. 
Kaennel M., 1998. Biodiversity: a diversity in definition. In: Bachmann P., Köhl M., Päivinen R. (Eds.), Assessment of biodiversity for improved forest planning, Kluwer, Dordrecht, 71-81.

Konijnendijk C.C., 2004. Enhancing the forest science/policy interface in Europe: urban forestry showing the way. Scand. J. For. Res. 19(Suppl.): 123-128.

Kuhn T.S., 1962. The Structure of Scientific Revolutions. Univ. of Chicago Pr., Chicago, 173 p.

Mendoza M.A., Fajardo J.J., and Zepeta J., 2005. Landscape based forest management, a real world case study from Mexico. For. Ecol. Manage. 209: 19-26.

Mulloy F., 2004. Closing address. In: Baines C. (Ed.), Forest Research Crossing Borders. EFI Proc. 50: 149-150.

Nobis M. and Wohlgemuth T., 2004. Trend words in ecological core journals over the last 25 years (1978-2002). Oikos 106: 411-421.
Schlaepfer R., 1997. Ecosystem-Based Management of Natural Resources: a Step Towards Sustainable Development. IUFRO Occasional Paper 6: 30.

Seppälä R., 2004. How to respond to emerging research needs in Europe: trends affecting forest research and strategies to face them. In: Baines C. (Ed.), Forest Research Crossing Borders. EFI Proc. 50: 147-148.

Soutrenon A. and Delatour C., 1998. Vingt ans de traitements de souches à l'urée contre Heterobasidion annosum en France (Base de données du Cemagref). Rev. For. Fr. 50: 217-229.

Ter Braak, C. J. F. and Šmilauer P., 2002. CANOCO reference manual and CanoDraw for Windows user's guide: software for canonical community ordination (version 4.5). Microcomputer Power, Ithaca, New York.

White A. and Hernandez N.R., 1991. Increasing field complexity revealed through article title analyses. J. Am. Soc. Info. Sci. 42: 731-734. 